\title{
Jet-A-Way Inc.: Winning Despite the Odds
}

\author{
Bonita L. Betters-Reed \\ Lynda L. Moore \\ Simmons College School of Management
}

\begin{abstract}
This is the hand that God dealt me and I am going to play it Darlene Jeter, 1991.
\end{abstract}

Darlene Jeter, co-founder of Jet-A-Way Inc., a recycling and waste disposal company, became CEO in 1991 upon the death of her husband, Eddie Jeter. Despite a recent loss of almost $50 \%$ in their company's revenue, Jeter decided to keep the cards she was dealt, playing for the longer run.

Today, Jet-A-Way is a seventeen million dollar company. A certified minority-owned business near downtown Boston, Jet-A-Way became known as a family-run company that gives back to the community in jobs and in service. Now Jeter and her team face new challenges - a volatile industry, production issues and the succession of her son Jesse Jeter as CEO while Darlene shifts her role to "Madame Chair."

\section{Jet-A-Way}

In 1991, before Darlene Jeter became CEO of Jet-A-Way, a recycle and disposal company, the company was on the verge of failure. Increased competition, difficulties in the production line and a severe economic downturn, resulting in a near $50 \%$ loss of revenue had convinced her husband and business partner, Eddie Jeter, to sell the company when he succumbed to cancer. But after his death, Darlene decided to risk playing the cards she was dealt, confront the serious debt they had incurred and play the game for the longer run return to success.

Success came after much due diligence. Revenue was up by 1992 and the company turned a profit by 1994. (Appendix A.) Throughout the 1990's Jet-A-Way grew not only in size but also in notoriety. Established as a double certified minority business two miles from downtown Boston, Jet-A-Way became known as a family run company that gives back to the community in jobs and in service. Darlene Jeter's leadership has been recognized by the Greater Boston Chamber of Commerce, the U.S. Small Business Administration, the Big Sister Association of Boston, the Massachusetts Black Legislative Caucus, and the National Solid Waste Management Association Hall of Fame. The leadership team she developed since 1991 has described her leadership style as unique. This story is about that leadership and the foundation of a company entering a new era. (Appendix B.) 
Today, Jet-A-Way is a seventeen million dollar company. Darlene Jeter and her team face new challenges of a volatile industry, increasing competition, tough economic times and the bumpy installation of a new production line. Added to this environment is a major anticipated shift in Darlene Jeter's role to "Madame Chair of the Board" as her son Jesse Jeter prepares to take over as CEO.

Jet-A-Way is located in Roxbury Massachusetts, part of the greater Boston municipality (Appendix C). They provide solid waste collection services, construction and demolition (C\&D) collection services for commercial customers and collection of materials for recycling. The company is licensed to process 750 tons per day of C\&D debris in their 25,000 square foot transfer station. The Department of Environmental Protection has established a waste-recycling goal of $88 \%$ by 2010 and Jet-A-Way has reached an $80 \%$ level. Further efficiencies are projected with the re-engineering of their plant. Jet-A-Way has 78 employees, over $2 / 3$ minority, and owns and maintains 36 vehicles and 500 open-top roll off containers.

\section{The Leadership Team}

In 2003, Jet-A-Way Inc.'s internal leadership team consisted of Darlene Jeter the CEO, Pat Coady, Vice President of Operations, Ronald Ciesluk, Vice President and Chief Financial Officer and Jesse Jeter, the Vice President of Business Development (Appendix D).

Pat Coady started working for Jet-A-Way in 1975 as a driver. He was promoted to foreman in 1978, supervised the transfer station in the early 80 s and was promoted to Operations Manager shortly afterward. He became VP of Operations in 2001.

Jesse Jeter is the youngest of the four Jeter sons. He grew up with the business. He became the VP of Sales and Marketing in 1998 and became the VP of Business Development in 2003. He has an MBA and BA in Economics.

Ron Ciesluk joined the company in 1996 as its Chief Financial Officer and brought with him extensive administrative and financial management experience. His formal education included a BSBA in Accounting \& Finance and an MBA. In 2001, Ron was appointed VP in addition to his role as CFO.

The leadership team also included a Chief Operating Officer/Executive Vice President who had many years of operations management experience and worked in close partnership with Darlene. This COO left Jet-A-Way in 2004 and the position was not refilled. 


\section{Leadership Core Values}

"Service is our Difference", the Jet-A-Way motto, reflects their strategic positioning as the high-end provider among the competitors. As Jesse Jeter says, "our job is to locate and develop relationships with businesses that have a high demand for excellent service" (Appendix E). This focus on excellence in service requires high standards across the firm and nowhere is this more evident than in human relations. As a small firm, Human Resource Management is functionally located with the finance part of the operation, but is also noticeably implemented across the organization in a strong commitment to providing internal opportunities for development and advancement.

Dan Dellamano came on board in 1999 as a driver, worked for six months and was promoted to lead driver. Since then he has become the Supervisor and Dispatch Operator, heading the entire driving unit. He comments that:

Everyone is outgoing and understanding, we are like a family and try to help as much as we can. I have moved up the ladder quickly...they came to me, they noticed, they see the potential in people and we always try to hire within the company first.

Pat Coady, Vice President of Operations, has a similar story to tell that spans a much longer tenure at Jet-A-Way. He came in 1975 also as a driver and his high level of productivity was immediately noticed and rewarded. He received a 100-dollar bonus with his first paycheck. Monetary rewards are used to this day for notable work and for incentive to work during holidays and tough periods. He was promoted to Foreman in response to an outside job offer. In the early 80's he was moved to the Transfer Station also managing the dispatch scale operation as Operations Manager. Coady became VP of Operations in 2001 overseeing Dan Dellamano and the Trucking Department, Maintenance, Transfer Stations and Customer Service. Pat has learned to be a good manager from Darlene. He comments on her confidence in her people:

She (Darlene) has showed me how to handle negative situations ...think about it first and ask questions of people with knowledge to help make decisions...in some cases she says, 'you make the decision' and you are always confident that she will back you up, her word is gold.

Darlene Jeter frequently comments that she cannot run the business alone, that you can only do it with others helping. Pat Coady provides insight into how this belief in others creates a highly functioning team:

When it comes to tough times, she knows how to motivate others - whatever it takes, we know we can do better, we just have to figure out how to get there...she (provides) good inspiration as a learner, someone who is patient, sees opportunity and expresses gratitude - every night Darlene says 'Thank You”.

This appreciation of employees and commitment to their development appears to be based on a clear understanding that it is the people that make the real difference and 
they must pull together to be successful. Employees are part of the extended family and Darlene firmly believes that "when your business is not successful, it hurts everyone. All of the senior management has an open door policy. Yet, it is perhaps Darlene Jeter's bigger view of employment that drives the supportive and nurturing culture. "Our company provides employment which brings money so employees can invest in their families, communities, and education.

\section{$\underline{\text { The Industry }}$}

Jet-A-Way Inc. is in the solid waste management or municipal solid waste (MSW) sector of the waste management industry (also known as environmental services). This sector in its broadest sense consists of waste collection, automatic disposals through landfills or incineration, recycling generally through transfer stations and waste-to-energy. Most of these services can be commercially and/or residentially based. The waste management industry is highly price sensitive, regulated at municipal, state and national levels, and directly tied to the economy, particularly housing and building growth. The government restricts inter-state disposals and Massachusetts has decreased its landfills significantly in the last decade. Recycling costs are greater than disposal costs creating a slow down in municipal recycling. It is an old male dominated industry in which the current competitors will fight to keep current contracts and new entrants are quick to see gaps and opportunity.

The Big Dig in Boston, the largest public construction project in the world, brought in increased demand for C\&D services, but it also created a truck driver shortage in an occupation that is frequently unionized. Truck driver turnover was high at Jet-A-Way. Although these many challenges make for an interesting industry, this level of uncertainty can also be a real impediment to effective planning.

\section{$\underline{\text { Competitors }}$}

Jet-A-Way's major competitors in Massachusetts are Waste Management Inc. (WM), a company with $\$ 11.2$ billion dollars in revenue, BFI (owned by Allied Waste Industries) with $\$ 5.5$ Billion in revenues and Atlantic Waste Systems (owned by Casella Waste Systems) has $\$ 421$ million in revenues. WM owns and operates multiples sites in Massachusetts, and offers, residential and commercial waste collection and disposal services via several transfer stations. BFI offers 9 waste hauling sites, owns its own landfill, and has a transfer station in Boston along with two recycling centers. Atlantic Waste Systems owns and operates one site in Peabody Ma, approximately 30 miles north of Boston. They offer waste collection, a transfer station, recycling and disposal services.

\section{The Origins of Leadership}

Darlene brought a strong commitment to her maternal legacy when she took over the business in 1991. Born and raised in Lorain, Ohio, she learned the importance of a strong work ethic and the value of entrepreneurship at an early age. Three generations 
of women were her role models: Great Grandmother Rebecca, Grandmother Mary Margaret and her mother "Ma".

Rebecca was an entrepreneur because she canned and made pies. I would help her at age five. Everyone who ate in her house worked. We sold the pies and canned goods. That was a good lesson...the importance of the work ethic.

Her Grandmother Mary Margaret was also a baker. Sugar cookies were made in the old fashioned way... cookies were rolled out using a cookie cutter and decorated. They were packed in old yellow potato chip cans, using wax paper as a separator and stored in the basement. The annual project started at Thanksgiving and continued every evening till Christmas. Literally hundreds of cookies were made. Putting in long hours and being disciplined were a must. As Darlene says, "Learning to stay focused was important; otherwise it wouldn't have gotten done. Mom taught us to work hard and stay with any project until it was done."

The cookies were given to shut-ins, the elderly, and the nursing homes. While Darlene's family was poor, they focused on helping those less fortunate. This legacy of generosity and social responsibility influences Darlene's community involvement and philanthropic activities today. Her charitable giving has been primarily directed to two not-for-profit organizations in the Boston area, Lena Park Community Development Corporation and the Big Sister Association of Greater Boston. Lena Park's mission is to provide high quality service and programs to the underserved residents of Roxbury, Dorchester and Mattapan, three of Boston's poorest and most underserved neighborhoods. Community focused educational programs, affordable housing, early care and adolescent services are provided. The Big Sister Association is a mentoring program for girls designed to cultivate confidence, competence and caring to help them attain life goals. Attention is given to creating access to information and resources girls need to make decisions about their future. Both of these organizations provide services to empower individuals and help communities become self-reliant.

Darlene's leadership challenges in Jet-A-Way continue to draw upon the team skills, hard work and dedication that began with baking and selling sugar cookies. The early years at Jet-A-Way however presented a series of challenges that tested this commitment and focus.

\section{Leadership Challenges}

Jet-A-Way was debt ridden and in the throes of a recession when Darlene took the reigns in 1991. With the initial idea that the company had to be sold, Darlene, with the help of her management team, drove costs down. Long hours and hard work enabled them to turn things around. More stringent safety programs to cut back on accidents and worker's compensation costs were implemented. The company's administrative offices were moved from an office building into a string of trailers at the company' transfer station. An aggressive cost reduction program and development of the sales force helped the business to grow. These combined efforts helped the company regain 
solvency and profitability. The company remained in debt throughout 1992, in 1993 began to break even and as profits returned in 1994, the company began to refocus on growth. (Appendices F \& G).

The late 90's continued to pose some tough problems for the company. Jet-A-Way had to absorb successive increases in disposal costs because of contractual obligations with their customers that prevented them from passing on these added costs. Ron Ciesluk explained that "it was at times like this that we fully recognized that we are not the masters of our own destiny in that we do not have our own landfill and are thus at the mercy of those who do." This situation began to correct itself in 2001 as these contracts began to expire. Additionally in 2001, Ron initiated refinancing of their Industrial Revenue Bond which ultimately dropped their borrowing rate by $50 \%$ from $10.5 \%$ to $5.34 \%$ and would save the company over $\$ 2.5$ million over the next 10 years.

During this time, Darlene also consulted extensively with her COO. With his substantial operations and business background he helped Darlene address issues in a planned manner and helped to formalize company policies and procedures.

Focused problem solving and an empowered team helped Jet-A-Way maneuver through the tough times. The team focused on "what had to be done". In the eighties investments were made to update equipment. The nineties posed problems regarding maintenance and continued effectiveness with aging equipment. "We had to think strategically about where to invest" comments Director of Operations Pat Coady. Despite the challenging times in the disposal industry, Jet-A-Way was able to invest $\$ 6.5$ million in new equipment of which more than 96 percent was funded through operating cash.

Darlene's willingness to learn from others and develop an external team was evidenced in the evolution of the Board of Trustees. The original Board was "really advisory" according to Darlene. It consisted of 15-18 people with a three year term. In 2002, Darlene decided to downsize the Board to 6 people, scale the expertise and interest of members to core resources and use their contributions more strategically. The Board addressed issues such as purchasing another company and investing in new equipment. A separate family Board was established at the same time. It consisted of Darlene, her four sons, two lawyers and an executive coach. This team, which meets quarterly, was charged with addressing the firm's leadership transition.

\section{The Plant Closing Crisis}

In November 1999 the company faced a complex problem. With no notice, The Department of Environmental Protection (DEP) closed two landfills. As a result there were 500 tons a day coming in and Jet A Way's facilities filled up quickly. The plant was closed for three days because there was nowhere to take the fill. 
The Department of Environmental Protection (DEP) Master Plan restricted the amount of excess waste produced in Massachusetts, one third of which was construction and demolition, Jet A Way's core business. The DEP stated that by the year 2010, firms should be recycling $88 \%$ of waste material.

With this DEP recycling goal in place, it was improbable that new landfills would be built. Furthermore, residents throughout Massachusetts were vehemently opposed to the replacement of landfills within their communities. As landfills became scarce, companies had to search for new and creative solutions. The subsequent looming ban on the disposal of asphalt, concrete, metal, brick, cardboard and wood led Jet-A- Way to expand its processing and recycling capabilities. The company was then capable of recycling nearly $80 \%$ of its incoming tonnage. Jet-A-Way recognized the importance of being in the forefront of recycling technology and positioned itself to meet the increasing requirements of the DEP's Solid Waste Master Plan.

\section{The Union: Local 379}

In the period of the late 1990's through 2000, Boston's "Big Dig" project drew many drivers because they were able to pay more (briefly explain Big Dig). Jet-A-Way tried to recruit licensed drivers and trained them to use their equipment. Problems with attendance and accidents led to a higher turnover rate of 27 drivers in the last two years. Because $50 \%$ of materials in the facility came in on Jet-A-Way trucks, drivers are critical to the company's success. New drivers began to discuss the need for more supervisory control and better benefits. Jet-A-Way provided better pay, but the pension plan was a $401 \mathrm{~K}$ with company matching funds. With the union plan, the pension is fully funded by the employer. Employees asked to have supervisors fired and Darlene, seeing no good reason to do so, refused. Employees had promised to unionize if their request was not honored, but Darlene refused to fire employees for which there was no performance problem. While the longer-term employees did not vote for the union, the newer drivers did. Darlene was disappointed, but with her usual straightforward approach moved forward to comply with the union contract.

On January 16, 2003 Local 379 was voted in. The management team acknowledges the "silver lining" aspect of unionization: the company got union jobs, and enhanced the quality and longevity of the drivers. While unionization has provided more experienced drivers, it has added some substantial cost to Jet-A-Way's bottom line. However, according to Pat Coady, the leadership team "expects with clear rules things will go well."

\section{Plant Modification Crisis}

While the union transition was occurring, talk of plant modification started. In 2002, faced with declining profit margins, increasing competition, new DEP regulations to increase recycling performance and an outdated plant (Appendix $\mathrm{H})$, the decision was made to re-design the plant with new equipment that would significantly increase Jet-AWay's capacity and improve recycling efficiency. 
Jet-A-Way's production of $40-50$ tons per hour was handicapped by equipment that had been in place since the company opened. They wanted to eliminate the high costs of bull dozers fuel and repair while improving shredder productivity early in the process. They invested $\$ 3$ million dollar's worth of new equipment which required re-engineering of the production line and the addition of an annihilator on the front end. CBI, an engineering firm in $\mathrm{NH}$, was responsible for equipment modification and installation.

From the beginning, the design and installation of the new equipment was fraught with problems. Late delivery of the Annihilator, an electronically powered, high torque slow speed shredder, in February of 2002 and an extended period of installation due to initial debugging slowed production down. Consequently, material backed-up and long lines started to form as their peak season commenced in March. From late May and throughout the summer they were only able to produce 30 tons per hour at best. Frequent shut-downs were necessary to ascertain the cause of equipment failure. Pat Coady initiated crisis intervention meetings with both shifts to get the information they needed and rectify the emergency itself. But, problems continued to escalate and the hydraulic pumps and motors failed causing the annihilator to cease operation on September 13, 2003. So on top of thousands of dollars already spent, they listened to the advice of technicians from three companies and invested another $\$ 45,000$ to get the annihilator repaired and the plant up and running.

Different perceptions of the problems, finger pointing within Jet-A-Way and with $\mathrm{CBI}$, and a tremendous sense of urgency created a series of short term reactive responses that appeared to only add to the confusion and acceptance of the situation. Darlene captured this sentiment quite clearly:

I was used to thinking it's not that hard... why are we failing? We've got an excellent location and reputation. We should be doing at least break even, not this. And every day I would think, 'what can we do to stop the bleeding?'

Pat Coady acknowledged that "we made an assumption that this wasn't going to be too difficult to do, but oh, what a surprise it turned out to be." In retrospect, everyone agreed that the timing was terrible, that perhaps they should have waited until their New Bedford competitor piloted the same equipment. In particular, Jesse Jeter wishes he had listened to his gut, "I believed that we were doing it incorrectly...I didn't think the technology was a bad idea. It was the timing." Reflecting upon his role at a family board meeting early during the crisis, Jesse adds, "I think if I was (more) forceful during that session, along with some of the other board members, it might have been enough to push that decision (about timing)."

The former COO's over riding desire to make the equipment work prevented management from getting any critical input from the line. Jesse recalled that this individual was leading the way, reminding him of a "commander" saying "I'm going to lead in this. I was victorious before, l'll be victorious this time." Subsequently, the Recycling Transfer Station (RTS) Plant Manager, felt pressured to make the new 
equipment work. Pat Coady later learned that some of the plant personnel identified potential problems with the conveyor belts before they were installed, but this information "never went any further than the project manager". Both Pat and Darlene acknowledge that the plant manager had been "promoted beyond his capabilities" indicating that trouble shooting went undocumented and personality conflicts interfered with information flow to management. Pat noted that it eventually became apparent "that we probably needed to make a change...the plant manager opened the door by telling us he was leaving."

Still plagued with break downs and serious financial loss, the leadership team decided to hire an experienced RTS manager and through word of mouth found Stan

Banalewicz. While Stan was getting his feet on the ground, Darlene came to grips with the severity and impact of the ongoing crisis, "we have to accept the fact that the machinery was just not working, we did not have faith in it, we were throwing good money after bad...we had a terrible year." During this critical time, Ron Ciesluk, Vice President and CFO, was not available due to ankle surgery. Having lost many of their biggest and oldest customers and confronted with a million dollar loss, Darlene consulted with an attorney and an outside accountant who advised, "You'd better do something and do it damn quick". Subsequently she made the decision to ask the COO to leave. Acknowledging that she had listened to the wrong person, yet she was the one ultimately responsible, Darlene took control:

I'm not going to continue to argue... it was friction all of the time about a company that I am responsible for. If it doesn't work, the most they (employees) lose is a job or employment, or they go somewhere else. I lose everything. So I made the decision that this can no longer continue.

The COO left Jet-A-Way in early January, 2004 and Darlene indicated that "we're all in agreement that we should not hire a person (replacement)...I really think that it would be a mistake...it would be a real downer for the ones that have really pitched in."

The addition of Stan to the management team provided fresh perspective and more experience to tackle the level of problem solving demanded by the very complex plant modifications. Redeploying the old bull dozers and giving up on the annihilator, Pat and Stan implemented a more thorough documentation system and tried new approaches to making the line work. Downtime dramatically decreased and conversely RTS production rose (Appendices I and J). By February, 2004 they reached a goal of consistently maintaining 45-50 tons per hour. The next goal of minimizing down time and processing 70 tons per hour was reached March 6, 2004.

\section{Going Forward - Recovery First}

Entering spring of 2004, their busy season, Darlene and her team were focused on the day to day operations necessary for a successful turn around for the company. Prior to the installation of the new equipment, Darlene had thought that Jesse's succession to her position was imminent and strategic diversification would be his greatest future 
challenge. But all of that changed with the threat of losing the business as she noted with seriousness and ever present good sense of humor:

We have a couple, maybe two to three years of recovery. This isn't going to go away overnight, not that kind of loss...I took a $20 \%$ pay cut too. And I think, yeah, I can manage, but just the same because of the losses and (because) the bank was here and I felt that we had to show them a lot to keep their comfort level...I took the pay cut. So naturally l'm not shopping like I used to.

Jesse agreed with this shift in attention to the immediate future. He was faced with regaining long-time customers and restoring the customer base:

...the theory says when you bring them (customers) back you've got to bring them back at a lower price, because why would they come back (otherwise)?The good news is, we've been in business for 35 years and we've got a great reputation, so we can bring them back.

As Vice President of Business Development, Jesse was training someone relatively new to Jet-A-Way, Robert Katilus, to take over the Sales Management part of his job. Jesse, hoping that this transition works, commented that "I can't leave until someone takes over my role."

Another personnel change at Jet-A-Way during the plant crisis created opportunity for a new degree of professionalism for the company. The hiring of Stan Banalewicz from the "outside" was a big move for the firm. Jesse, in particular, expressed that Stan added 'some things to the company that were real good building blocks' for Jet-A-Way. He further elaborated on this contribution:

...he's outside trained; he knows more than just his job. He understands the politics of business. He's pretty articulate. He brings in a different professional dynamic to the company that we're not used to. For the most part, (our) people have been Jet-A-Way trained, Jet-A-Way culture. He's not Jet-A-Way culture. He's a different culture.

Darlene reinforced this cultural change by clearing the way at the top; a very difficult challenge for her given her legacy of care and support for her people and a strong bond with her $\mathrm{COO}$ of 13 years. But it was one of the very difficult lessons she learned, "As I say, I would never, ever let it go this long (again)." Explaining the delay in this decision Darlene noted, "I became somewhat attached to people and then you take your eye off of the prize....paying more attention to the person (than the problem)."

The loss of the COO opened the door for an important strategic role to be filled by someone else. Reflecting upon the COO's strengths Jesse summarized his leadership and what Jet-A-Way was missing as a result: 
He wasn't really involved in the day to day operations of the company, and I think that's critically very wise.... good leader...ensures that the day to day operations survive and do well without him... he did that. I think we'll miss him from the next step actions perspective. He was involved with 'what do we do next'? Where does this company go next from a growth standpoint?

Jesse acknowledged that while no one has talked about it, he believes that they'll miss his strategic perspective and adds, "I'm hoping that's something I can pick up."

Jesse was concerned that with COO gone, Darlene no longer has a buffer between her and the rest of the organization. This too had an impact on role changes for Jesse and the other managers as Jesse noted, "We had to put on our big boy shoes, Ron, Pat and myself, we had to (watch) what gets kicked up (to Darlene)....how much stress can she handle and how much did she want to handle at this point?"

Darlene is the first to acknowledge that the past year took a tremendous toll on her personally, "I lost 25 pounds and didn't sleep well at all. Holding a promise to take her daughter-in-law and three daughters on a vacation while in the throes of the business crisis, she spent the whole time thinking about 'how bad things were back at home' and she agonized:

You've got 78 people that are counting on you for their livelihood. Oh, true they could go out and find employment elsewhere, but just the same, a lot of them have many years invested here, and that gave me great concern.

This was the hand that Darlene Jeter was dealt. Drawing upon a strong leadership legacy and many lessons learned, she is confident about playing these cards, "you know I will survive." She projected that Jet-A-Way's recovery will continue for about two to three years more, "and then we're going to work with Jesse to get him to the point that he basically will do what I'm doing now, and then I can step back." 
Appendix A: Summary Sales \& Profits 1990 to 2002

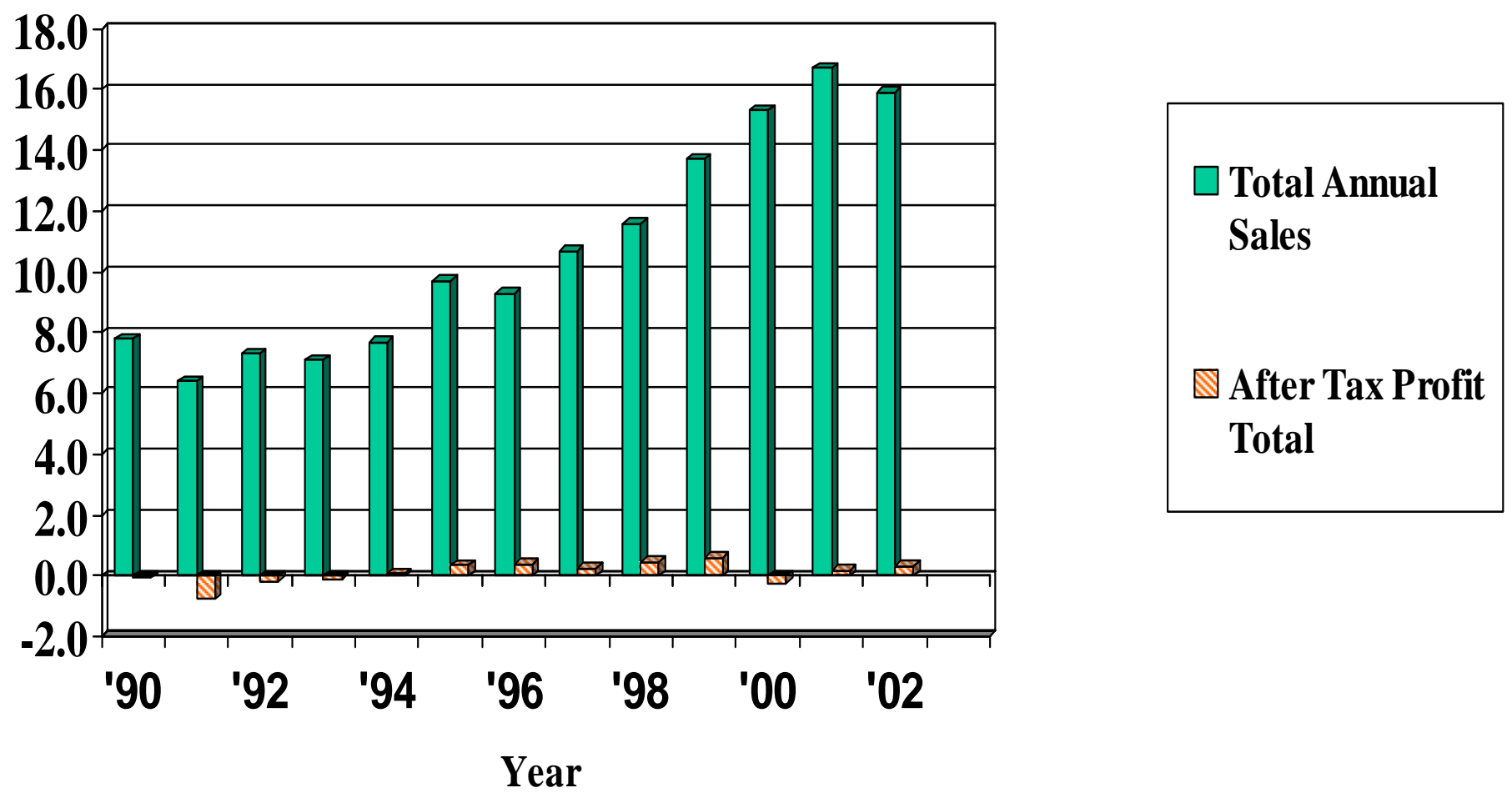




\section{Appendix B: Timeline of Significant Events}

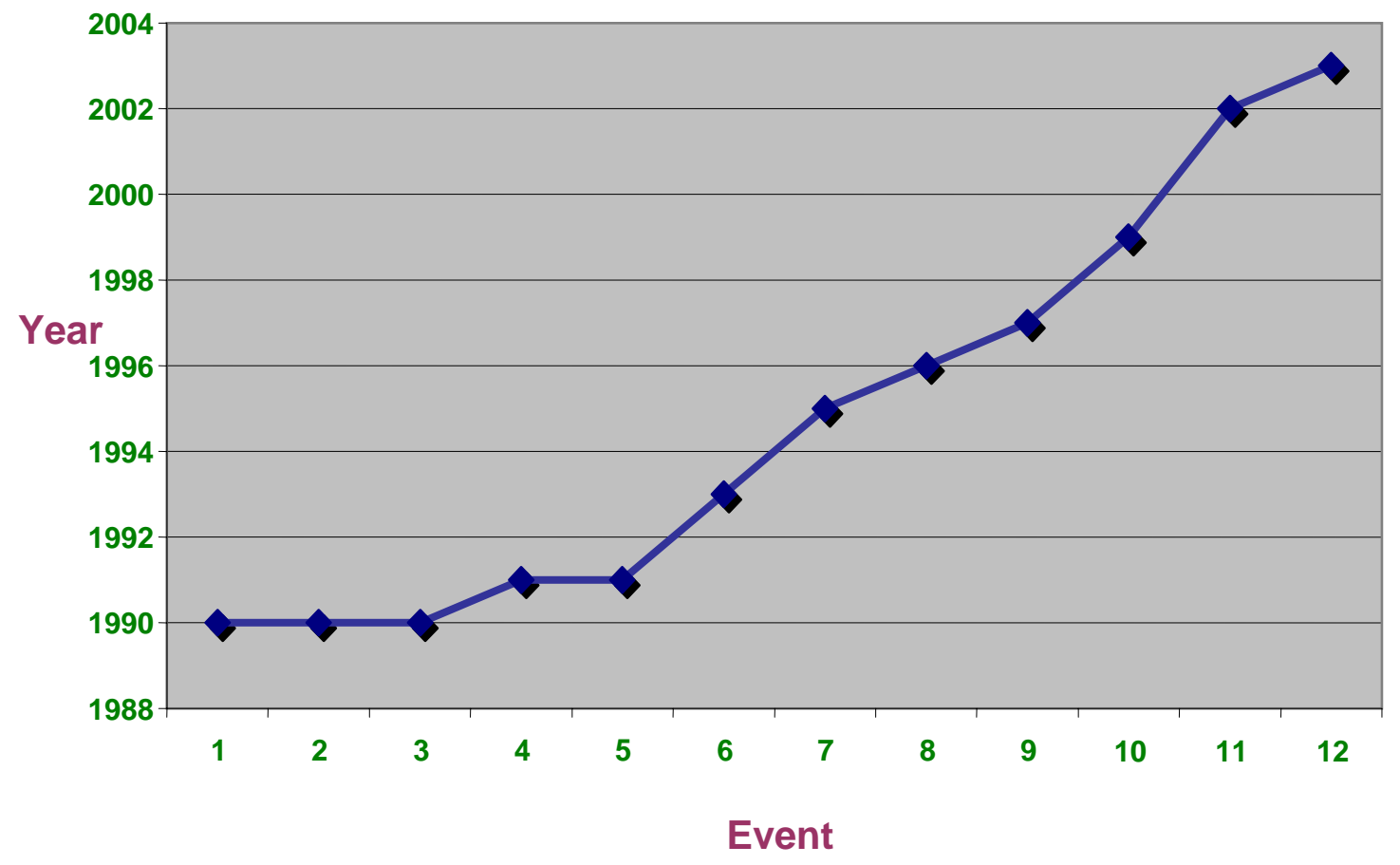

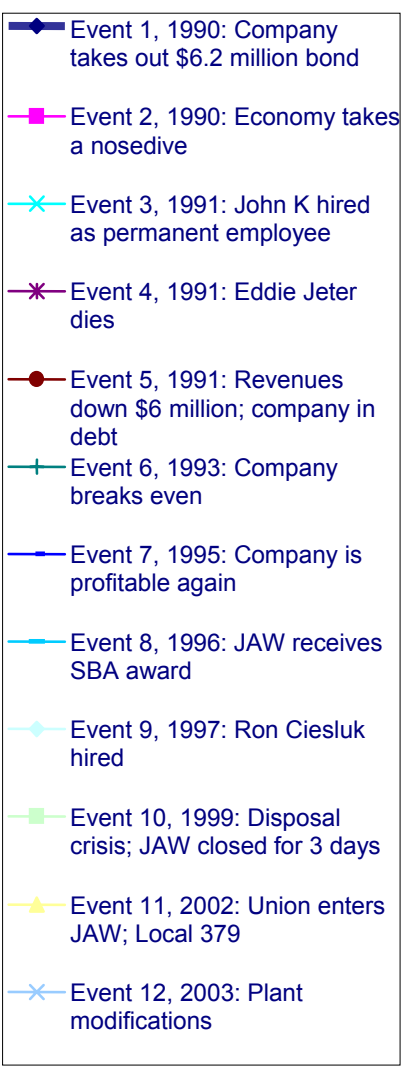




\section{Appendix C - Greater Boston Map}

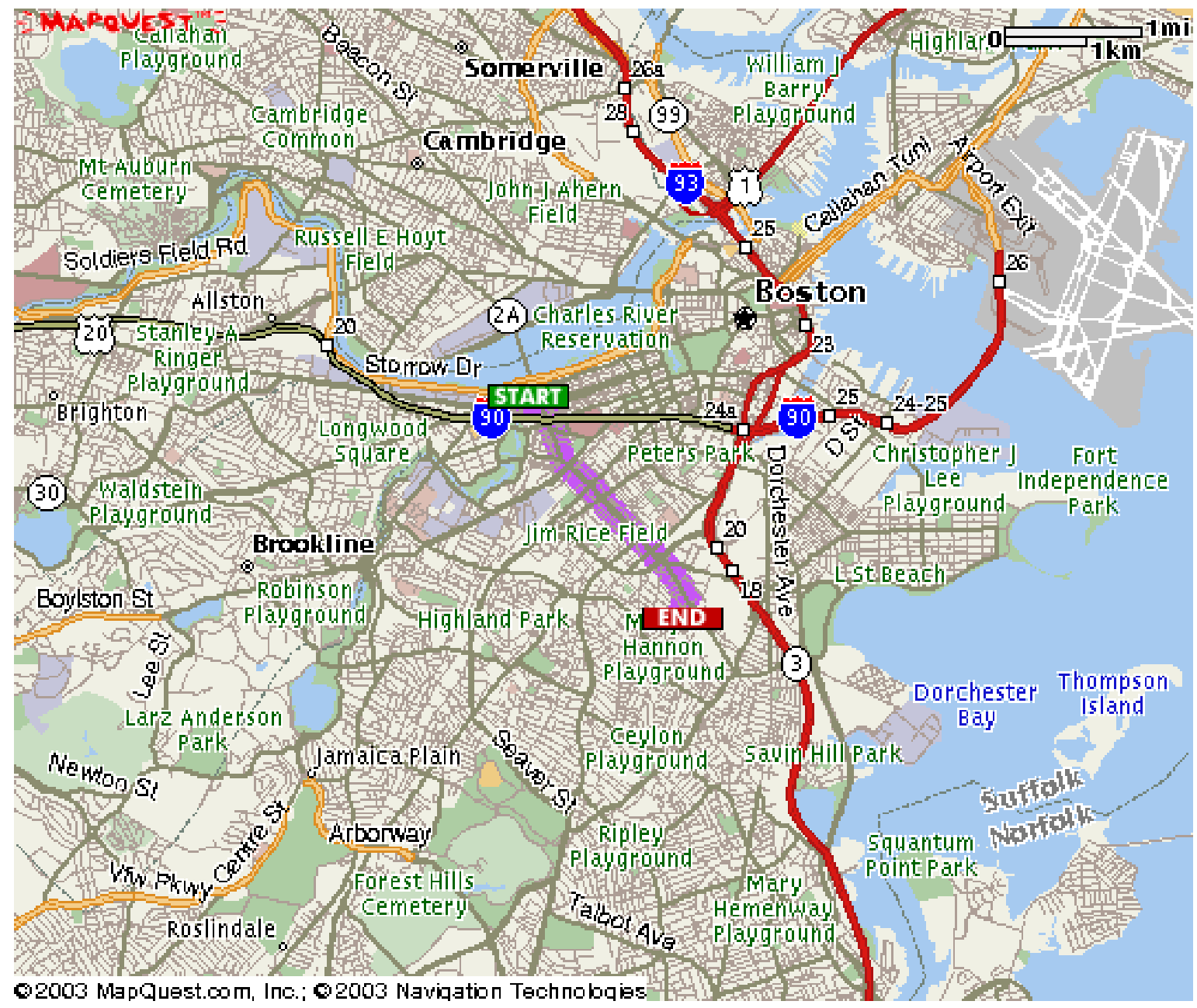




\section{Appendix D - Jet-A-Way Organization Chart}

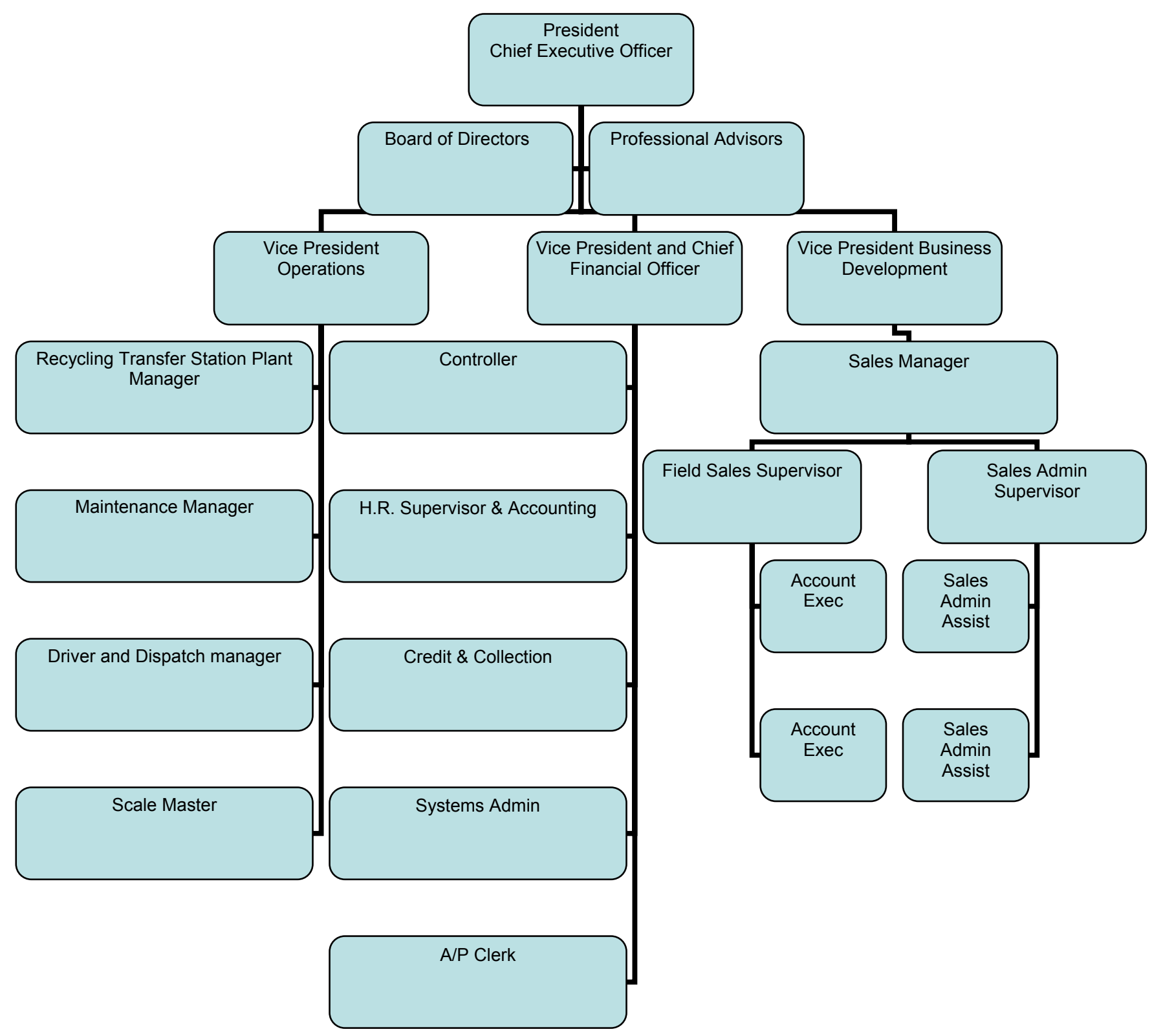




\section{Appendix E: JET-A-WAY, Inc.}

\section{Mission Statement}

TO LEAD IN THE RECYCLING, TRANSPORTATION, AND DISPOSAL OF CONSTRUCTION AND DEMOLITION DEBRIS

* To be competitive IN SOLID WASTE AND RECYCLING

\& TO SERVICE CUSTOMERS IN AN EXEMPLARY MANNER, ALWAYS ACTING WITH THE HIGHEST OF ETHICAL STANDARDS

* TO PROVIDE A PROFESSIONAL WORK ENVIRONMENT THAT ENCOURAGES EVERYONE TO WORK TOGETHER CONSTRUCTIVELY AND SAFELY FOR THE COMMON GOOD

\& TO TREAT CUSTOMERS, VENDORS, COWORKERS, AND OUR COMMUNITY WITH RESPECT AND DIGNITY

\& TO ACT RESPONSIBLY WITHIN THE COMMUNITY BY PROVIDING OPPORTUNITIES FOR EMPLOYMENT AT COMPETITIVE LEVELS OF PAY AND UTILIZING FAIR POLICIES THAT WILL SUPPORT THE TRAINING AND PERSONAL DEVELOPMENT OF OUR EMPLOYEES

\& TO MANAGE MATERIALS IN AN ENVIRONMENTALLY SAFE AND PROPER MANNERI

\& TO BE A PROFITABLE AND SUCCESSFUL COMPANY TO SUPPORT FUTURE GROWTH AND DEVELOPMENT 
Appendix F: Percentage of Sales Growth 1990 to 2002

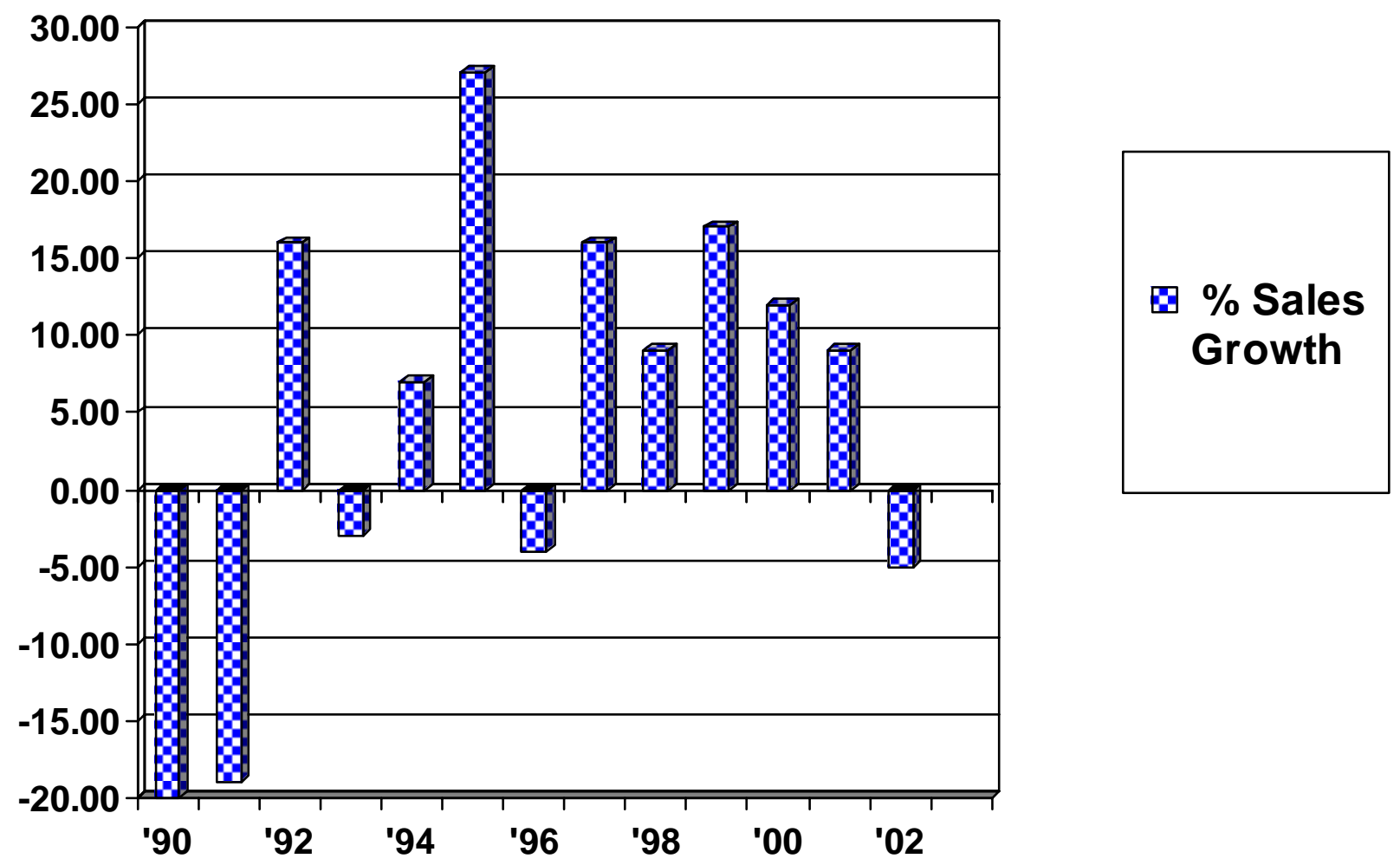


Appendix G: Profit as Percentage of Sales 1990 to 2002

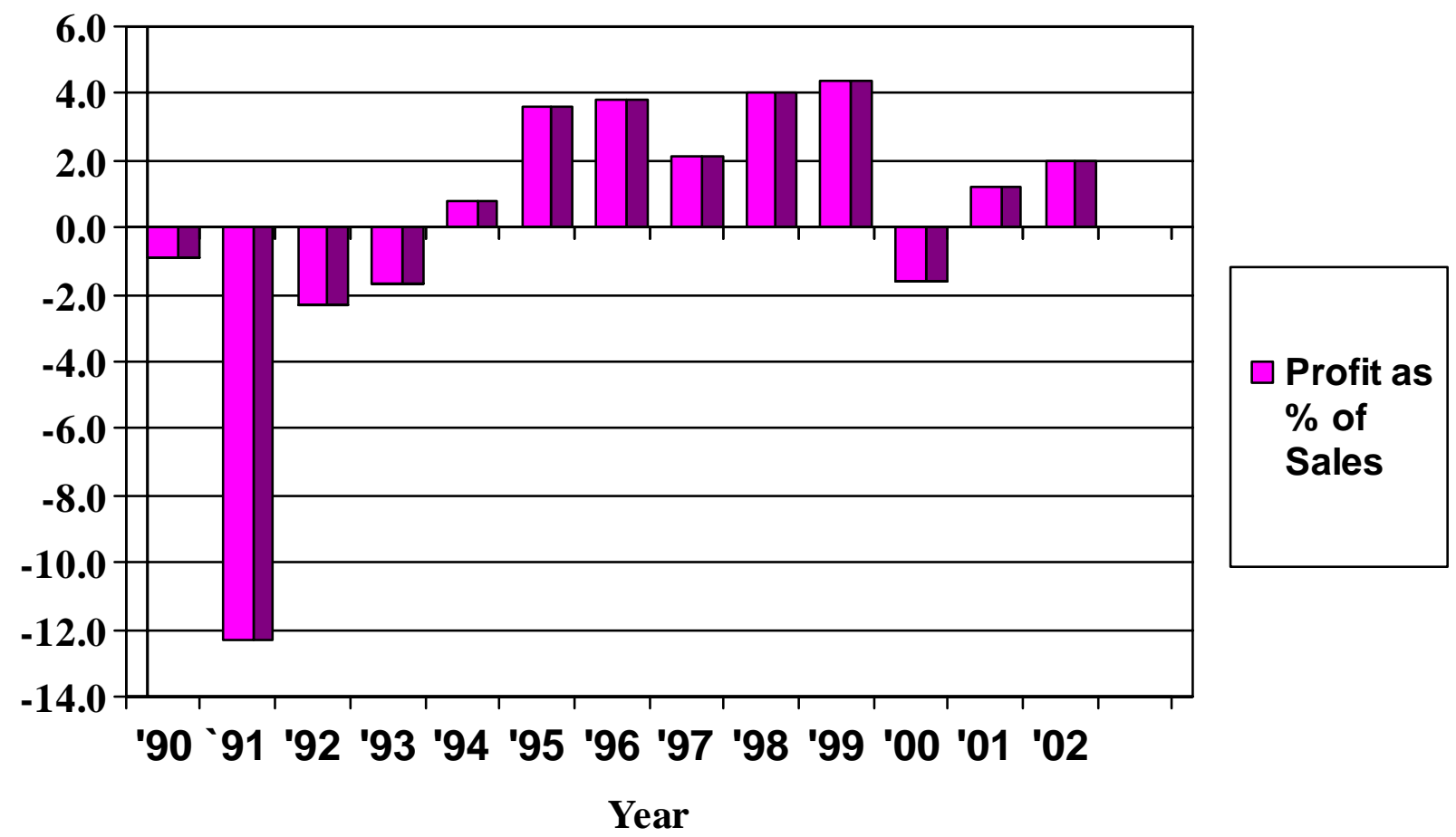




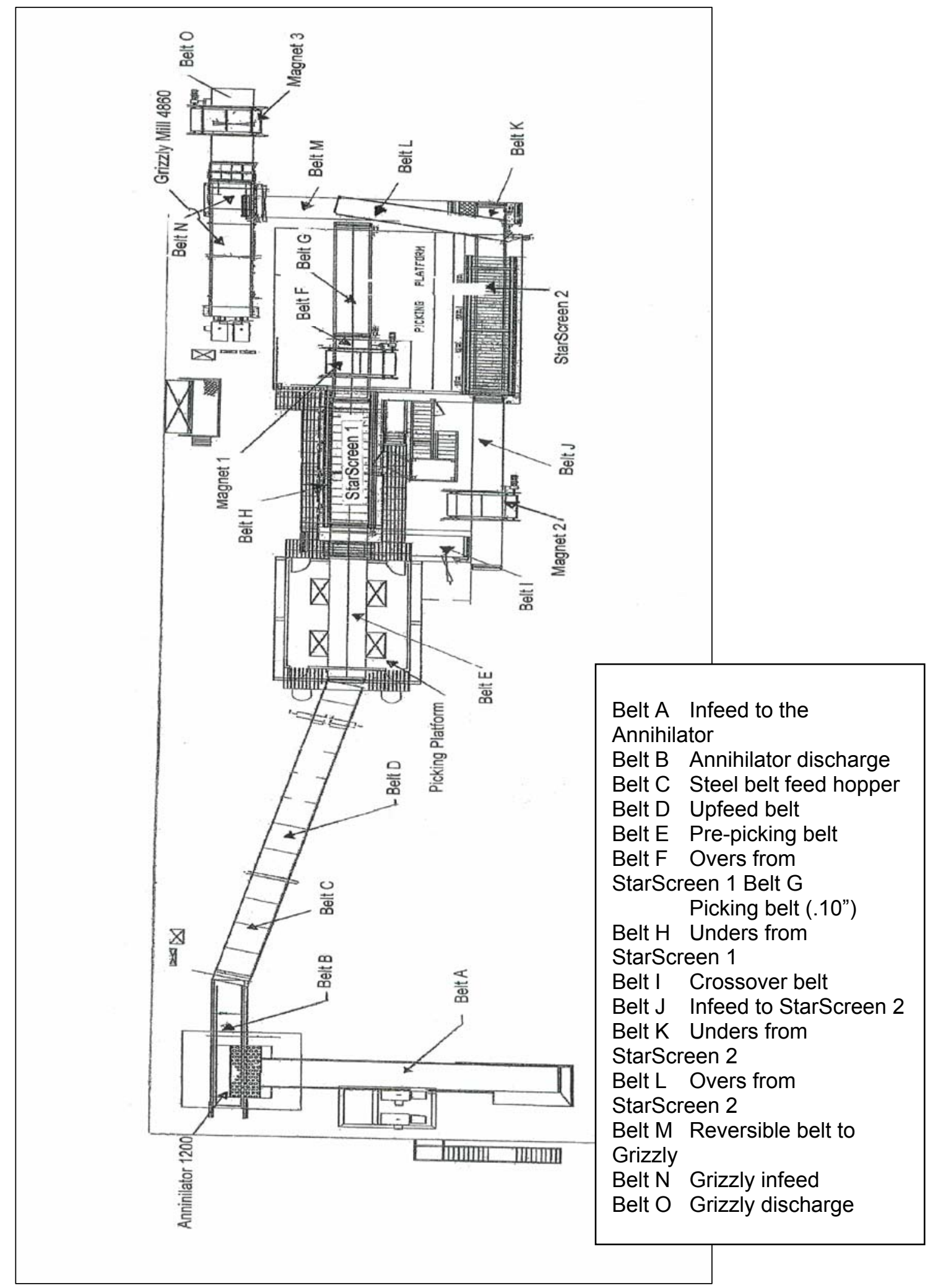


Appendix I - RTS Production

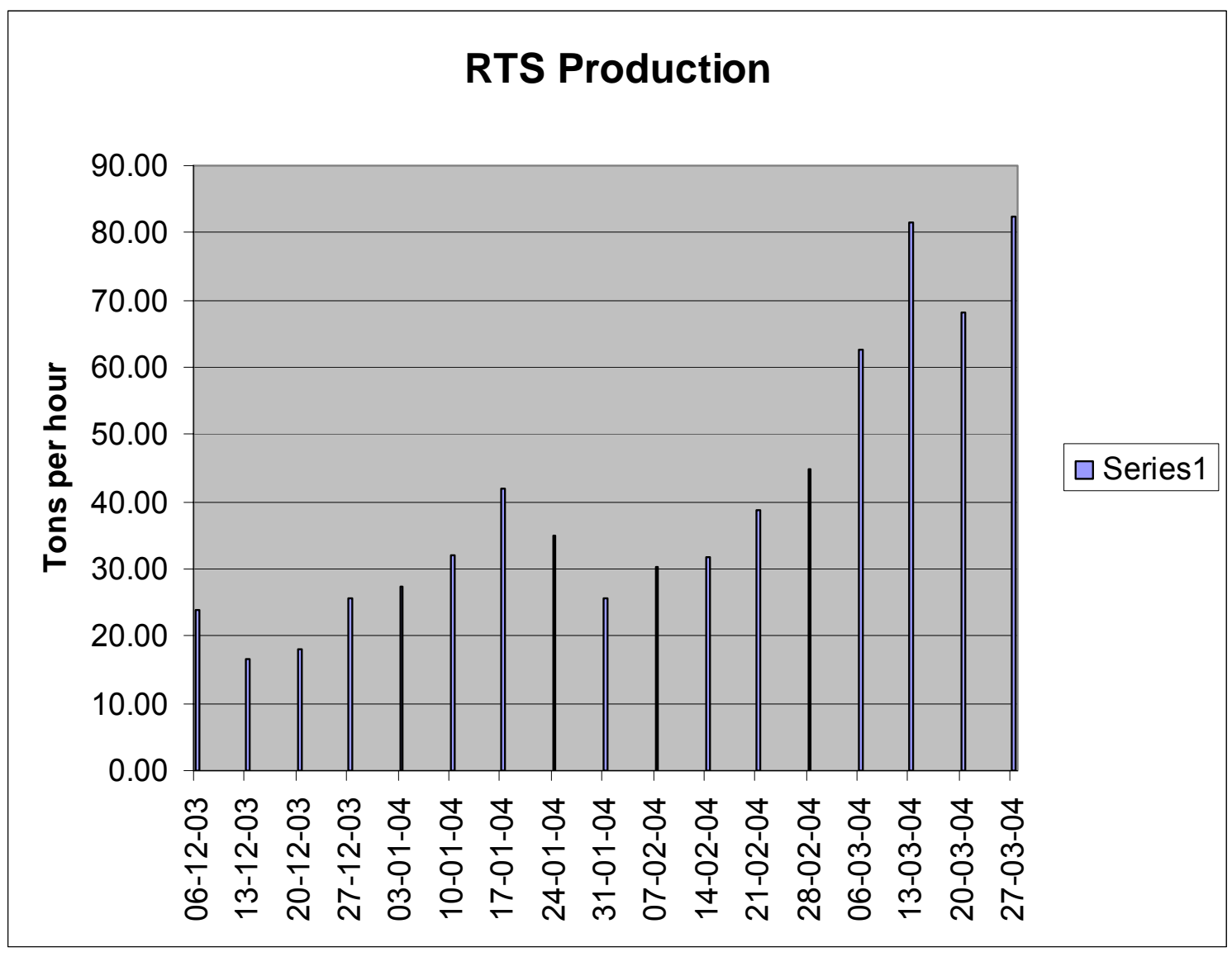


Appendix J - RTS Downtime

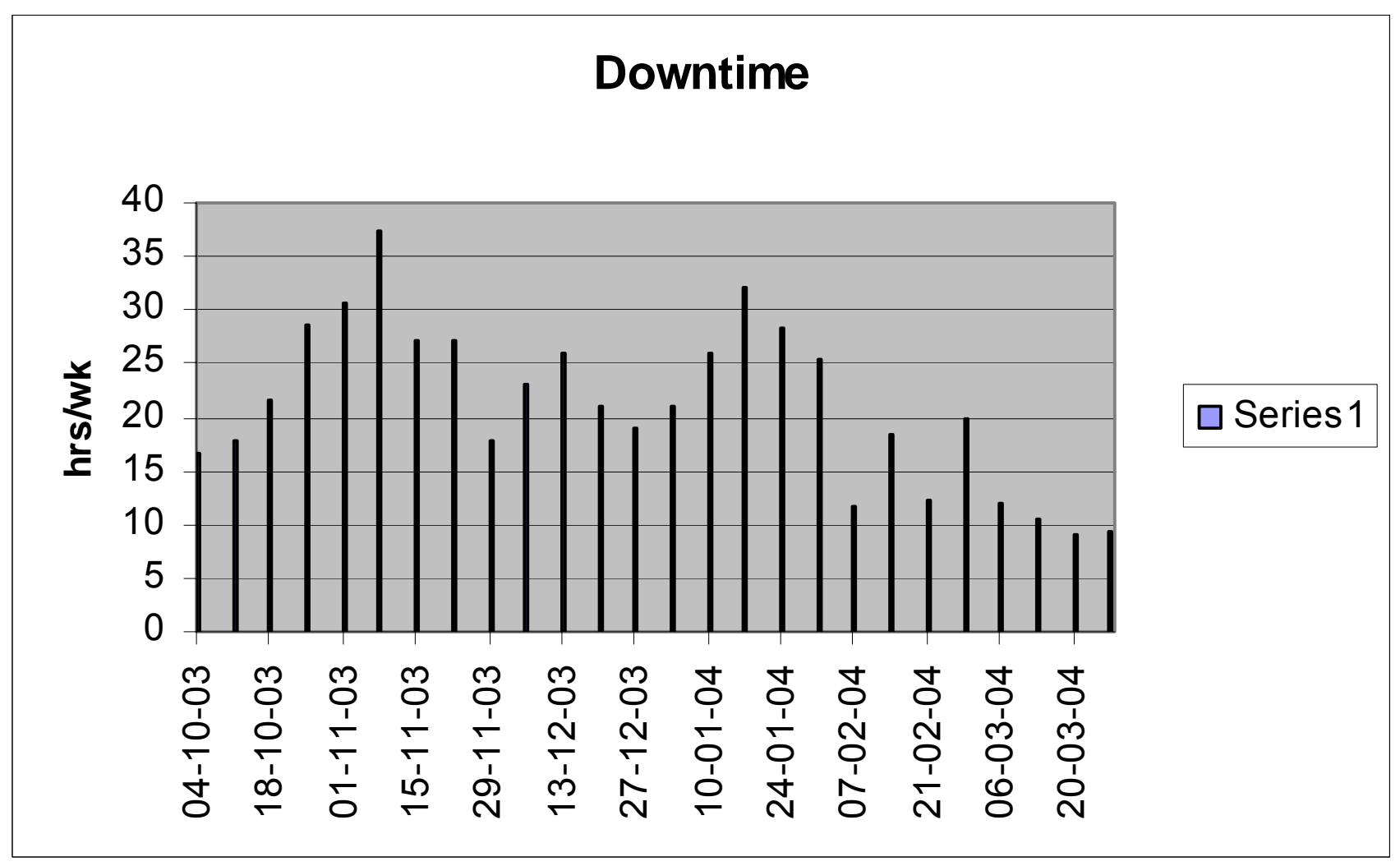




\section{References}

Ackerman, Jerry. (1997, September 10). 1600 small firms gain. MassBusiness: Fast Track. The Boston Globe.

Ciesluk, Ronald, K.. Jeter Case Study Notes: Interview with Ron Ciesluk. interview by Bonita Betters-Reed, March 28, 2003.

Ciesluk, Ronald, K. Jeter Case Study Notes: Interview with Ron Ciesluk. Interview by Lynda Moore, March 28, 2003.

Coady, Patrick. Jeter Case Study Notes: Interview with Patrick Coady. Interview by Bonita Betters-Reed, March 31, 2003.

Coady, Patrick. Jeter Case Study Notes: Interview with Patrick Coady. Interview by Lynda Moore, March 31, 2003.

Cullen, David. (1999, December). Getting the Clean Sweep: Fleet Owner, Primedia Business Magazines \& Media, Inc., ISSN: 0731-9622.

Daniels, Steve. (1997, August 18). Coming Back: C\&D Outfits Survive Slump. Crain Communications, Inc.

Darlene Jeter. Jeter Case Study Notes: Interview with Darlene Jeter. Taped proceeding done by Bonita Betters-Reed and Lynda Moore with an audio cassette, June 27, 2003.

Darlene and Jesse Jeter. Jeter Case Study Notes: Interview with Darlene Jeter and Jesse Jeter. Taped proceeding done by Bonita Betters-Reed and Lynda Moore with a video cassette, November 7, 2003.

Dellamano, Daniel. Jeter Case Study Notes: Interview with Daniel Dellamano. Interview by Bonita Betters-Reed, March 31, 2003.

Dellamano, Daniel. Jeter Case Study Notes: Interview with Daniel Dellamano. Interview by Lynda Moore, March 31, 2003.

Gendron, Marie. "Chamber names Jet-A-Way Small Business of the Year" The Boston Herald May 15, 1996

Howe, Peter J. (1989, June 18). \$10 million recycling plant to be built in Roxbury. The Boston Globe.

Jackson, Derrick. (1990, December 2). The grunt end of working for ecology. The Boston Globe. 
Jeter, Darlene. Jeter Case Study Notes: Interview with Darlene Jeter. Interview by Bonita Betters-Reed, February 24, 2003.

Jeter, Darlene. Jeter Case Study Notes: Interview with Darlene Jeter. Interview by Lynda Moore, February 24, 2003.

Jeter, Jesse. Jet-A-Way's Total Sales, Profit as \% of Sales, Fiscal Growth as \% of Sales. Jet-A-Way April, 2003.

Jeter, Jesse. Jeter Case Study Notes: Interview with Jesse Jeter. Interview by Bonita Betters-Reed, 04/14/2003.

Jeter, Jesse. Jeter Case Study Notes: Interview with Jesse Jeter. Interview by Lynda Moore, 04/14/2003.

Jordan, Robert A. (1991, September 21). Farewell to a quiet hero. The Boston Globe.

Kelso, John. Jeter Case Study Notes: Interview with John Kelso. Interview by Bonita Betters-Reed, February 24, 2003.

Kelso, John. Jeter Case Study Notes: Interview with John Kelso. Interview by Lynda Moore, February 24, 2003.

Kelso, John. Jeter Case Study Notes: Interview with John Kelso. Interview by Bonita Betters-Reed, March 24, 2003.

Kelso, John. Jeter Case Study Notes: Interview with John Kelso. Interview by Bonita Betters-Reed, Lynda Moore, March 24, 2003.

Management Team Meeting. Jeter Case Study Notes: Management Team Meeting. Taped proceeding done by Bonita Betters-Reed and Lynda Moore with an audio cassette, July 1, 2003.

McNabb, John K. Jr. (1999, December 2). Letters To The Editor: The Wrong Way to Handle Waste. The Boston Globe.

McQuarrie, Brian. (1999, November 25). Haulers dump on state over lack of landfill space. Say recycling goal not being met. The Boston Globe.

Muller, Joann. (1996, June 26). Jet-A-Way’s long haul. The Boston Globe.

Rodriguez, Cindy. (1998, November 11). City fines Roxbury waste site operators. The Boston Globe.

Rosenberg, Ronald. (1996, September 18). Small business group honors Darlene Jeter. The Boston Globe. 
Ryan, David L. (1997, March). How I Did It. Essence Magazine.

Scharf, Stewart. (2003, April 24). Industry Surveys: Environmental \& Waste Management. Standard \& Poor's.

Staff Reporter. (2003, February). Chartwell Information Solid Waste Digest at www.wasteinfo.com.

Staff Reporter. (2003, June 1). Waste Age 100 Waste Age.com at www.wasteage.com.

Unknown staff writer. (1990, December 14) Bond Plans worth $\$ 91 \mathrm{~m}$ face board's vote today. Boston Globe City Hall Bureau. The Boston Globe.

Unknown staff writer. (1998, May). Darlene Jeter: Surviving the Rough Stuff. Waste Age News.

Unknown staff writer. (1999, December 14). Coming Back. Waste News, Crain Communications, Inc, ISSN: 1091-6199.

Unknown staff writer. (2001, June 25). Hauling \& Disposal Rankings. Crain Communications, Inc., 